\title{
The role of social support in contributing to posttraumatic growth in persons with vision impairment
}

\begin{abstract}
BACKGROUND
Some individuals report transformational growth understood as lasting positive changes following adverse experiences. Recently psychological research has attempted to understand the complex relationship between adversity and subsequent growth. In 1995 Tedeschi and Calhoun coined the term "posttraumatic growth" (PTG), which is also termed "adversarial growth" by Linley and Joseph. PTG has become a leading area of research, striving for a balanced positive psychology that integrates the complexity between the negatives and positives to optimise positive outcomes. Therefore, the purpose of this study was to elucidate the role of social support in contributing to PTG in three study cases.
\end{abstract}

\section{PARTICIPANTS AND PROCEDURE}

The qualitative approach was based on semi-structured interviews with three women over 50 who lost vision when they were 18, 25 and 43 years old. Two of the participants were Polish, and one was Australian. The Ecological Systems Theory (EST) of Bronfenbrenner was used to demonstrate changes, as its process-person-context model permits this investigation.

\section{RESULTS}

This study revealed that social support contributed to the PTG experienced after vision loss in the cases studied. Participants stressed that the received social support enhanced their gratitude and helped them grow in many unexpected ways. The relation characterised by the synergy between social support, gratitude and growth has been suggested by the participants.

\section{CONCLUSIONS}

The trajectories of PTG in these studies varied and were influenced by individual resources and the socio-cultural contexts of the participants.

\section{KEY WORDS}

posttraumatic growth (PTG); social support; Ecological Systems Theory (EST); vision impairment (VI)

ORganization - Salesian Pontifical University, Rome, Italy AUthors' Contributions - A: Study design - B: Data collection - C: Statistical analysis - D: Data interpretation .

E: Manuscript preparation · F: Literature search · G: Funds collection

Corresponding Author - Bożena M. Sztonyk, Department of Psychology, Salesian Pontifical University, Piazza dell'Ateneo Salesiano 1, 00139 Rome, Italy, e-mail: bozenapng@gmail.com

TO CITE THIS ARTICLE - Sztonyk, B. M., \& Formella, Z. S. (2020). The role of social support in contributing to posttraumatic growth in persons with vision impairment. Health Psychology Report, 8(3), 238-247. https://doi.org/10.5114/ hpr.2020.96896

RECEIVED 08.04.2020 • REVIEWED 15.05.2020 • ACCEPTED 03.06.2020 • PUBLISHED 03.07.2020 


\section{BACKGROUND}

The motif of finding benefits in the midst of hardships has been recognised in many cultures and religions for centuries (Tedeschi, Park, \& Calhoun, 1998). In psychology, however, it is a relatively new concept. In 1995, Tedeschi and Calhoun coined the term "posttraumatic growth" (PTG) to identify the phenomenon of "positive psychological changes experienced as a result of struggle with traumatic or highly challenging life circumstances" (Tedeschi, Shakespeare-Finch, Taku, \& Calhoun, 2018, p. 3) and measured it using the Posttraumatic Growth Inventory (PTGI; Tedeschi \& Calhoun, 1996). This concept has been also labelled as: "positive psychological changes” (Yalom \& Lieberman, 1991), "perceived benefits" (Calhoun \& Tedeschi, 1991), "transformational coping" (Aldwin, 1994), "stress-related growth" (Park, Cohen, \& Murch, 1996), "thriving” (O’Leary \& Ickovics, 1995) or "adversarial growth" (Linley \& Joseph, 2004), but the term PTG attracted the most interest. Research studies show that on average $60 \%$ of people report benefits in the aftermath of a traumatic event (Calhoun \& Tedeschi, 2006). The positive changes following adversity can be observed in three main areas: relationships, a philosophy of life and the perception of self (Joseph, 2009; Juczyński \& Ogińska-Bulik, 2012).

The PTG construct is focused on longer-term changes occurring in the post-trauma period (from days to years), where individuals develop "new ways of thinking, feeling, and behaving, because the events they have experienced do not permit a return to baseline functioning” (Tedeschi et al., 2018, p. 5). In that way PTG can be distinguished from "resilience" and "recovery", which lead to the baseline. What constitutes a traumatic event is broader than the event itself, defining trauma, as "its effect on schemas, exposing them to reconstruction" (Calhoun \& Tedeschi, 2004, p. 100). Arising from this, the focus is given to both subjective and objective qualities of trauma, defined by the authors as "a highly stressful and challenging life-altering event" (Tedeschi et al., 2018 , p. 4). Further, the authors admit that usually in the aftermath of a traumatic event people experience life-changing situations that cannot be simplified in terms of a single event since some circumstances may occur over a period of time and include many events (Tedeschi et al., 2018). With regard to the period of time between the stressful event and PTG, the data are inconsistent due to two factors. First, there is individual variability of the PTG trajectories over time. Second, measurement of time since the event may not be long enough to observe changes, as for some persons positive changes may only emerge over long periods of time (Helgeson, Reynolds, \& Tomich, 2006; Tedeschi et al., 2018). The common feature of PTG, despite the variation of traumatic events and the time since the event, is the fact that the changes people report after trauma are considered by them as positivetransformative development.

The constructivist, assumptive worldviews theory of Janoff-Bulman (1992) laid the foundations for the PTG process, in which it is believed that "people create individual versions of basic cognitive categories used to understand experience, and core beliefs about the self, their future, and their world" (Tedeschi et al., 2018 , p. 3). Moreover, the existential tradition in philosophy and psychology on suffering had a significant influence on the understanding of PTG. The works of Viktor Frankl (1997) outlining the search for meaning in all life's circumstances, termed as tragic optimism, was not only a foundation for existential psychology, but also a catalyst, among many other developments, for positive psychology to move towards integrating both positive and negative life experiences, in order to optimise positive outcomes (Wong, 2011). The discussion of the idea of growth following adversity, as an alternative view of how to think about trauma, was initiated with the intention to shift away from the medical model dominating psychology, towards human strengths and wellness (Joseph, 2009, 2019). This new perspective helps to view the human struggle with trauma in a way in which it can be seen as a "springboard to a greater level of psychological functioning" (Joseph, 2009, p. 341).

Social support as an aspect of PTG has been studied broadly; however, the results are not consistent due to the variety of operational definitions used (Joseph \& Linley, 2005). The relationship between social support and growth following trauma is found to be moderate (Prati \& Pietrantoni, 2009). The main role of social support is to help suffering individuals to optimise their resources to effectively cope with troubling conditions (Ogińska-Bulik, 2013). The most valuable support is when others motivate people to take responsibility for their lives (Joseph, 2011). The study findings indicate that seeking social support reflects an active coping strategy to deal with either the problem at hand (instrumental) or its emotional consequences. Further, seeking social support may be distinct from receiving or perceiving social support (Prati \& Pietrantoni, 2009). Ogińska-Bulik (2013) confirms that perceived and received support are equally important for the process of PTG. Support from close relatives can be crucial for traumatised individuals in development of positive changes associated with growth. Further, social support is associated with personal characteristics. A meta-analytic study on PTG and gender revealed that women are more likely to report PTG than men are (Vishnevsky, Cann, Calhoun, Tedeschi, \& Demakis, 2010). Consequently, women may benefit more from social support in being more prone to seek help and self-disclosure (Ogińska-Bulik, 2013; Vishnevsky et al., 2010). Tedeschi et al. (2018) pointed to
Posttraumatic growth in persons with vision impairment 
Bożena M. Sztonyk, Zbigniew S. Formella three stages in which social support can influence PTG: as a pre-trauma context factor (predictor), as a mediator, and then as an outcome. Thus, availability of strong social support before trauma occurs can help people cope effectively with adversity and may increase PTG. Similarly, having people who can provide constructive support while dealing with trauma may be crucial in changing life perspectives or serve as role models (when they have experienced similar circumstances). When social support is considered as an outcome, it (e.g. meeting new people in posttrauma support groups) can help to develop a stronger sense of connectedness to others and with the community. Social support seems to be influential in promoting PTG; however, its role is complex as "an intervening variable between personal characteristics of an individual, strategies used to cope with trauma, and consequences of the latter" (OgińskaBulik, 2013, p. 6).

Visual impairment (VI) is a multifaceted and heterogenous condition that is characterised as reduced ability to see, with difficulties related to the eyes and/or its connected nervous system (Colenbrander, 2010). In the International Classification of Diseases (ICD) the degree of VI is categorised into moderate to severe VI, blindness, and unspecific VI (World Health Organization, 2016). The number of persons with ICD-defined VI is estimated at about 285 million worldwide and about $80 \%$ of all cases globally are considered avoidable (Pascolini \& Mariotti, 2012). The experience of vision loss is potentially traumatic and can have major implications for people coping with it as well as for people close to them. In consequence individuals with VI are at higher risk of experiencing potentially traumatic events (PTEs) than the general population, especially threats in everyday life manifested in various stress reactions that may also impact their mental health (Brunes, Hansen, \& Heir, 2018).

The findings from a systemic review on psychological adjustment to vision loss in adulthood showed only 52 studies published between 1946 and 2014, indicating that this topic had rarely been presented in the wider literature (Senra et al., 2015). The studies pointed out that better adjustment to disability was associated with greater acceptance of vision loss, use of instrumental coping, good social support, positivity, and use of assistive aids (Senra et al., 2015). Few studies have examined positive changes after vision loss. Boerner, Wang, and Cimarolli (2006) found that negative changes after vision impairment were reported three times more often than positive changes in a variety of life domains. Positive changes involved increased compassion and empathy for others, increased self-worth, greater appreciation of life and placing a higher priority on family. In this study PTG was discussed as possibly causing significant life changes. Another study investigated age as a fac- tor relevant for growth following vision loss. After VI middle-aged adults reported experiencing more changes, both positive and negative, than those in older age (Boerner \& Wang, 2010). Considering all the above, PTG following VI in adulthood can be deemed to be an underdeveloped area of research.

The case studies presented here were stories of three women over 50 who struggled with traumatic vision loss after a considerable time of being sighted. The aim of this study was to broaden understanding of PTG and to find out in what ways social support influenced their personal growth in the aftermath of their VI.

\section{PARTICIPANTS AND PROCEDURE}

\section{STUDY DESIGN}

The systemic review has shown that psychological adjustment to vision loss in adults has not been studied in depth. Tedeschi et al. (2018) suggest "collecting data that captures the unique or ideographic experiences of people in rich and meaningful ways in order to understand the nuance of personally constructed lived experiences" (p. 85). The qualitative case study method was employed as it gives scientists a tool to study this wide-range view within their contexts (Baxter \& Jack, 2008). Additionally, "aspects of human behaviour are common in psychological case study research" (Hancock \& Algozzine, 2006, p. 32). This study intended to determine individual, interpersonal, cross-cultural, and developmental differences in the way these women perceived and expressed PTG.

\section{PARTICIPANTS}

Three women over 50 qualified for this study because they confirmed that loss of normal visual functioning during adulthood was for them a traumatic event that was highly stressful and life-altering. Two of them were Polish, while one was Australian. Their VI was a consequence of health-related causes in two cases, and the third acquired VI occurred during a terrorist attack. Although the origins of the traumatic experience differed, for all three cases vision loss was perceived as an adverse and traumatic life event. Participants' names were changed for confidentiality. Informed consent from each participant was obtained to begin the study.

\section{PROCEDURE}

After having the background of the study explained, each participant was advised on a study style. One 
participant agreed to have a face-to-face interview and two others via phone conversation, all following the same pattern of semi-structured interview. First, each participant responded to two questionnaires to obtain results without the prior deep reflection that in-depth interview could have elicited, if they had been done in reverse order. For the two Polish participants the adapted and validated versions of original tests were used. The tests' results were intended to supplement the data obtained during the in-depth interviews. These questionnaires were: the PTGI, a 21-item self-report measure that records responses to positive outcomes of the focal event that was previously identified as subjectively stressful that was adapted to Polish by Ogińska-Bulik \& Juczyński (2010); and the Multidimensional Scale of Perceived Social Support (MSPSS; Zimet, Dahlem, Zimet, \& Farley, 1988), a 12-question self-report to measure an individual's perception of support for 3 sources: family, friends, and a significant other, adapted to Polish by Adamczyk (2013). Second, the participants were asked to present the story related to the vision loss in a narrative way. The short narrative form was then followed by a semi-structured style of interviewing. There were two sets of questions: the first inquired about the experience of change that took place after the sight loss in regard to the different dimensions characteristic for PTG; the second investigated experiences of social support after the vision loss, regarding proximal and distal context with a focus on changes that were caused by trauma. All interviews lasted 90 minutes on average. The interviews were audio-recorded and transcribed verbatim. Two interviews were conducted in Polish and the responses were translated into English.

\section{DATA ANALYSIS}

The collected data from each case were then thematically analysed. First, the transcripts were read several times to reveal the key themes. Collected data were looked at in the light of the Ecological Systems Theory (EST; Bronfenbrenner, 1979; Bronfenbrenner $\&$ Morris, 2006). The nested structure of the micro-, meso-, exo-, macro-, and chrono system of social contexts permitted the investigation of human development and helped detect the patterns and interrelationships of multiple factors and allowed observation of the active role of the person at the centre. Further, the model of the Organismic Valuing Theory through Adversity (Joseph, 2011; Joseph \& Linley, 2005) assisted with the psychosocial perspective on PTG. This type of data analysis, which uses triangulation with reference to different theories, is intended to develop comprehensive understanding of phenomena as different perspectives can be helpful in data analysis (Carter, Bryant-Lukosius, DiCenso, Blythe, \& Nev- ille, 2014; Creswell, 2014). Researchers use theoretical perspectives as an orienting lens that "becomes a transformative perspective that shapes the types of question asked, informs how data are collected and analysed, and provides a call for action and change" (Creswell, 2014, p. 98).

\section{RESULTS}

Data analysis was guided by the Ecological Systems Theory to establish the role of social environments on PTG in the examined cases. Social support may either facilitate or impede the natural tendency to growth. Bronfenbrenner (1979) in his ecological theory noted that there are different levels of systems, cultures (distal and proximal). Families, groups, workplaces, and nations have their own cultures that can influence the way people think, feel, and respond to e.g. traumatic events. The EST scheme of person-processcontext-time named as: micro (parents, siblings); meso (further family, neighbours); exo (school, parish); macro (distal context - country institutions, culture); and chrono (lifespan) systems will be followed here; however, the data do not permit exploration of every aspect of the EST model (Bronfenbrenner \& Morris, 2006). Calhoun and Tedeschi (2004, 2006) admit that it is important to consider both proximal and distal contexts when trying to understand the PTG process. Additional data include the results from the administered questionnaires.

\section{JOANNA (AGE 57; POLISH)}

At present a university professor; born with low vision, who suffered vision loss at age 25 , due to an unsuccessful operation.

Test results: Overall PTGI score was 90 out of 105 (total score), which implies PTG. The overall score for perceived social support measured with the MSPSS was medium; significant others scored high (parents); family scored medium (further family); friends scored high.

Person-context: Joanna presented her personal strengths and resilience in a way that showed the effects of her parents' influence on her. She called them role models to follow as they were realistic and grounded persons (a theme repeated a few times in the interview). Similarly, loss of independence and the struggle to defend her own dignity frequently arose as topics. Joanna demonstrated personal effort and persistence when she explained how she had to prove her competencies to others. She adjusted her main goals as the circumstances changed. The aim of pursuing a scientific career, however, had not changed. She used her life projects as a way to raise her self-esteem. She had a strong feeling that she had
Posttraumatic growth in persons with vision impairment 
obtained some important things in her life despite life's challenges. She stressed that she was in control and planned things in her life. In Bronfenbrenner's terms she is an agent of her own development.

Proximal processes: These were limited to dyads: Joanna-parents or Joanna-Michal (a Polish writer, who lost vision and hands after WWII, to whom Joanna was introduced after she lost her vision). Since childhood it had been her parents who influenced the way Joanna coped and controlled her emotions. She mainly relied on her parents for mobility. Joanna admired Michal's attitude to life, and he inspired her to find a new meaning in life and change her life priorities to handle her blindness. She called Michal her role model.

Microsystem, mesosystems, exosystem: Joanna's interactions at these levels were again influenced by her parents' style of keeping problems and private issues to themselves. Joanna kept her extended family and neighbours at a distance. She dealt with problems using only her own resources.

Distal processes: Evidence of the macro-system can be seen in the limited services for disabled persons under the Communist system. Joanna particularly pointed to low tolerance in society towards persons with disabilities, and occupational problems. She stated that in the post-Communist era, there were better services for persons with disabilities, greater choice, but unsatisfactory help regarding employment and societal approaches to disability had not improved much.

Time: The sense of change over time can be appreciated by the fact that Joanna was born with low vision (genetic cause), which was corrected in her first year of life; then she functioned with corrected vision until the age of 25 . After she lost her vision, she was on a disability pension for 8 years, working independently on a doctorate. When she defended her doctoral thesis, she found employment at the university as a lecturer and continued in that way. In the meantime, her parents died, and she relied on others by asking for help with mobility.

Resources: Personal resources - competence, resilience, hardiness, persistence, strong will, being realistic and grounded; social resources - parents, some friends, Michal; material resources - a disability pension until employment.

Life motto: Not being able to see is not the greatest misfortune in life - summarised Joanna.

\section{RITA (AGE 51; POLISH)}

At present a social worker in Germany; at 18 diagnosed with progressive sight loss; then at 28 she regained partial vision after operations.

Test results: Overall PTGI score was 84 out of 105, indicating PTG. The overall score for perceived so- cial support measured with the MSPSS was medium; significant others scored medium; family scored medium; friends scored high.

Person-context: The diagnosis of her illness and subsequent vision loss made Rita vulnerable, helpless, powerless, hopeless and depressed. She repeated these words many times when describing herself. Her overriding aim was to act in rebellion at that time and that signified her lack of will to work on the acceptance of her loss of sight. Even though she felt as if she wanted to die, and had suicidal thoughts, she was determined to seek some help and answers from somewhere. When she did not receive it from close family, she searched further among friends. Despite her vulnerability she showed her strong will to survive. Rita in effect became stronger: however, her real strengths flourished when she regained her vision. On some occasions Rita still feels she wants to panic, but now she knows how to handle it and be in control. As a result of her challenges she feels stronger and empathic towards others who suffer.

Proximal processes: These were limited to a dyad: Rita-Zenek (a friend with multiple sclerosis who she met at the group for persons with disabilities where she volunteered before she got her diagnosis). Rita called Zenek her role model. He strongly influenced Rita in how to cope with disability and have a positive outlook. She felt confident to talk with Zenek about everything and she felt understood only by him.

Microsystem, mesosystem, exosystem: Rita initially exhibited emotional withdrawal and the avoidance of contacts with peers and those who initiated discussions of the problem. When she experienced a lack of understanding from her mother, she consequently distanced herself from her family and moved away. She avoided contacts with neighbours or government services as she was afraid of stigmatisation. She continued participation in a group of persons in wheelchairs where she met Zenek. She was seeking help from other friends and strangers and established new friendships. After she had her vision partially restored, she continued making contacts to get a job until she found one in Germany.

Distal processes: After her diagnoses, Rita did not seek assistance from professionals, and she was not offered any services. When she dropped out of school there was no investigation from the system into the reasons, nor any encouragement to complete further education. Rita noticed intolerant attitudes towards people with disabilities, and she felt stigmatised by people from the village. She experienced prolonged unemployment due to her status as a person with a disability even after she partially regained her vision. Society's attitudes towards those with disabilities are not satisfactory for her even now, and so is the lack of awareness of issues surrounding disability. 
Time: Rita was born with a genetic problem that began to affect her sight at the age of 18 (non-normative change). For ten years Rita was progressively losing sight and rebelled against it and stopped her education. When she underwent successful operations that partially restored her vision, she decided to finish secondary school and did a vocational course to seek a job but was unsuccessful with that and went abroad to help friends. While in Germany she was encouraged to learn German and then found a job, which she has continued up to the present time.

Resources: Personal resources - a strong will to seek help from others, faith in God; social resources - some new friends, finding a wheelchair group, Zenek; material resources - a disability pension until employment.

Life motto: What doesn't kill you will make you stronger - summarised Rita.

\section{ANNA (AGE 57; AUSTRALIAN)}

At present an accountant; lost her right eye in a terrorist attack at the age 43 , her husband lost his entire vision.

Test results: The overall PTGI score was 46 out of 105, suggesting posttraumatic growth. According to reports from Australia mean scores were significantly lower compared to the American population (Morris, Shakespeare-Finch, Rieck, \& Newbery, 2005). The overall score for perceived social support measured with the MSPSS was high; significant others scored high (husband); family scored high; friends scored high.

Person-context: It can be said that Anna coped well, right from the beginning. She immediately thought of her long-term friend Donna, who lost an eye in a car accident, and by doing so she regained hope. Anna decided to follow her usual pattern of rationalizing challenges to gather strength and to get ahead with life. She had learnt that from her family. At the beginning, she got a bit protective with respect to her eye as she felt responsible for the family to take over her husband's tasks. She was reluctant to receive help from others. She believed that she could do it all herself. She was open to listen to her mother-in-law's criticism of her attitude of refusing offers of help from others. She decided to challenge herself and see kindness in others first. She was able to understand that those young men who exploded the bombs were ignorant and too young to know much about life and the world.

Proximal processes: These were limited to dyads: Anna-husband; Anna-Donna (role model). Anna was strongly influenced by Donna in coping with her loss. She relied on her husband to lead as he used to do, while changing some roles regarding the usual tasks of driving and managing the budget.
Microsystem, mesosystem, exosystem: Anna's relations with her close family (parents and sister) did not change as a result of trauma (they did not get involved as they could see she was coping). The relationship with her husband did not change significantly - he is a leader, and she needs his strength. Her friendship circle did not change much. Her friend Donna who has monocular vision became her role model. She kept good relations with her mother-in-law. Along with her husband she was touched by the support they received from neighbours and strangers. Anna got support through her study time from the university as they adjusted some rules to her new life circumstances. She found new friends at the school where she got a job. They lost some friends but gained new, more genuine ones.

Distal processes: Anna praised the good medical system in her country and received support from professionals (she complained only about two of them); she feels that their situation is advantageous as they live in a first world country, an affluent one, and that their medical expenses were covered. However, people with disabilities still experience struggles to find a job in the mainstream market, Anna admitted.

Time: Anna was born with full vision; she lost her right eye in a terrorist attack in 2005; she returned to finish her studies where she found a new work opportunity as a vision support teacher; she worked in that position from 2009 to 2015 and now works as an assistant in the project run by her husband.

Resources: Personal resources - a strong personality, coping skills, openness to receive support from others; social resources - her husband, friends, mother-in-law, Donna; material resources - a stable financial situation from employment, having her medical expenses covered by government aide.

Life motto: People are basically kind. There are only a few that are flawed for various reasons, most people are kind, and they want to help, given the opportunity - summarised Anna.

\section{DISCUSSION}

These findings highlight the value of exploring psychosocial processes, especially positive changes with the population of persons who struggle with the adversity of vision loss after having grown up sighted. The three cases which were studied indicate that the participants in the aftermath of vision loss experienced some changes that resulted in the transformational growth expressed by these women, despite the diverse nature of their VI. In each case the trajectory of growth suggested individual, developmental and cross-cultural differences that elicited individual differences in trauma response. The overall scores from the PTGI indicated experience of PTG in each studied case.
Posttraumatic growth in persons with vision impairment 


\section{TRANSFORMATIONAL GROWTH}

The Organismic Valuing Theory of Growth through Adversity (OV) posits that "human beings are active, growth-oriented organisms" (Joseph \& Linley, 2005 , p. 269). The authors of OV add that new trauma-related information can be processed in either direction, in accommodating or assimilating new circumstances. Accommodation requires that a person change existing worldviews, whether the change

Bożena M. Sztonyk, Zbigniew S. Formella is in a positive or negative direction (Joseph \& Linley, 2005, 2008). It has been found that participants predominantly used the positive accommodative processes that directed them to accept and adjust to the new circumstances. Thus, they engaged their cognitive processes to rebuild existing assumptive worldviews in order to experience transformational growth. This indicates that participants were guided by an inner sense of growth, which is a fundamental position of OV theory. However, at times each woman resorted to assimilative and negative accommodation processes, such as denial or refusal of some changes, but this only demonstrates that OV processes are multifaceted and cannot be taken as mutually exclusive categories (Joseph \& Linley, 2008). Some positive changes pointed out by participants related to experiences of personal growth, changes in life priorities, heightened appreciation of life and people, feelings of gratitude and valuing relationships more, all indicate the characteristic domains of PTG (Calhoun \& Tedeschi, 2004). These, according to OV, reflect heightened psychological well-being. However, the participants admitted that at times they were still dealing with stressful and negative situations of VI. This confirms a main notion in PTG theory that stress can coexist with personal experiences of growth (Tedeschi et al., 2018).

\section{THE ROLE OF SOCIAL SUPPORT}

The EST assisted here to distinguish a role of proximal and distal contexts in the process of growth following VI. Calhoun and Tedeschi (2006) admit that "an individual's proximate cultural influences may provide a more direct avenue for evaluating how the process of PTG may occur” (p. 12).

\section{RESULTS FROM TESTS}

On the subscale of the PTGI that measured growth in relationships with others, each participant demonstrated growth, scoring above 21 out of 35 . Results from the MSPSS on perceived social support in studied cases ranged from medium (Joanna and Rita) to high (Anna). These indicate that perceived social support was an influential predictor of participants' cop- ing and subsequent growth. The qualitative analysis focused then on received social support.

\section{PROXIMAL CONTEXT}

It was found that having social support (resources) in the pre-trauma and post-trauma period affected the process of growth (Tedeschi et al., 2018). The received social support varied in each case; for some it was the reflection of their pre-trauma situation (Joanna received limited social support, involving mostly her parents, who influenced her style of keeping further family and neighbours at a distance); for others the struggle with trauma created an opportunity to change attitudes and expand coping resources (for Anna it was openness toward receiving help offered by others - a new ability that she has learned). Seeking social support was found to be a salient coping strategy when dealing with adversity (Ogińska-Bulik, 2013; Prati \& Pietrantoni, 2009). Lack of support from Rita's family spurred her to seek help among friends and strangers, and they accompanied her at the time she faced her progressive vision loss. The source and nature of support are also important variables in predicting PTG. Anna and Rita mentioned that they had gained new friends who were more genuine and helpful, but also noticed that some stopped contacting them, which is aligned with other findings on PTG (Tedeschi et al., 2018). Joanna received social support (prior and after trauma) from her parents, who believed in her and taught her how to face her adversity, which increased her chances of transformational growth. Joanna was sure that her personal hardiness and need to be in control resulted from her upbringing. In other cases, lack of social support from close family members in the aftermath of crisis was considered as an initial impediment (in Rita's case).

Social support can also be considered as a mediator between individual difference variables and PTG. Tedeschi et al. (2018) claim that having someone who provides constructive support may assist in developing positive changes contributing to expereince of PTG. Some studies demonstrated that the presence of someone who can model post-trauma outcomes has resulted in greater positive adaptive capacity for trauma victims and a great source of received emotional support (Morris, Shakespeare-Finch, \& Scott, 2012; Tedeschi et al., 2018). The women from this study also testified to the influence of having a significant person - a trauma survivor - who was recognized by them as a role model and was of central importance to their growth (parents and then $\mathrm{Mi}$ chal who lost sight and hands were role models for Joanna; Zenek with MS was for Rita; Donna with monocular vision was for Anna). Their role models accompanied them in struggling with loss and 
provided valuable information and skills on how to cope with challenges, and how to survive psychologically. Most importantly, all the women admitted that these persons inspired them to grow and understood them best.

The recent academic discussion on PTG poses the dilemma of whether the growth following trauma represents subjective or objective change. Hobfoll et al. (2007) in accordance with their conservation of resources theory suggest action-focused growth, whereas Calhoun and Tedeschi (2004) focus on subjective changes. It has also been noted that turning growth into the mission of service to others is viewed as a final phase in the PTG process (Calhoun \& Tedeschi, 2013; Tedeschi et al., 2018). Each woman studied shared her new empathetic attitudes towards others in response to her own experience of facing trauma and receiving social support. In the end, they opened themselves up to be of service to others. Joanna dedicated her many years working on a doctoral project to focus on gathering data on the literature of those with VI. She also has been lecturing on subjects related to disability, making students aware of the needs and dignity of persons with various disabilities. Rita has been involved in different volunteer services for people with disabilities and often defends the rights of persons with disabilities and works professionally in the social care sector. Anna decided to work for many years as a vision support teacher, where she took the opportunity to become a model for VI students.

\section{DISTAL CONTEXT}

This study allowed observation of some aspects of the sociocultural factors that participants emphasised during their interviews, which represent their personal views and experiences of dealing with VI in a broader context. However, the study did not intend to make any wide-reaching cultural comparisons. In the case of Poles their reflections spanned from the period when Poland was under a Communist ideology, up to the present time of democratic government. This had the unique value of showing the transformational process that also impacted on the studied cases as they pointed to personal struggles exacerbated by external, distal factors of living in society where the rights of persons with disabilities were not seen. It would be remiss to exclude such a general observation. The Australian participant praised the support received from the government; however, she along with the Poles pointed to existing discrimination towards persons with disabilities in the mainstream employment market.

On many occasions during interviews participants expressed their gratitude for received support. Gratitude in recent studies was found to be associ- ated with PTG (Joseph et al., 2012). It can serve as a coping strategy (Wood, Joseph, \& Linley, 2007) or as important experience of wisdom and growth (Linley, 2003). An experience of gratitude fosters the development of social support (Wood, Maltby, Gillett, Linley, \& Joseph, 2008).

In summary, the role of social support in contributing to the process of PTG in the cases studied was important. The intertwined influences of individual and sociocultural factors - proximal and distal prove that the PTG process is complex and varies in individual trajectories. In cases studied the relation of synergy was observed, between a participant's received social support and subsequent growth that is also reflected in their decision to return the received goodness to those whom they found in greater need. Some participants admitted that they actively searched for support from close family members and even strangers, as it proved to be a successful coping strategy. They also emphasised the indispensable role of other trauma survivors who modelled their emotional coping with vision loss. Participants' gratitude seemed to serve also as a coping strategy and to build up a greater network of social support.

\section{LIMITATIONS \\ AND RECOMMENDATIONS}

This study has limitations that need to be pointed out. First, there were three cases studied, too small a number from which to draw any general conclusions. Second, the participants represented two distinct countries, which was an interesting aspect when EST guided the analyses of distal contexts experienced by participants. The aim of this study was to more fully understand the role of sociocultural elements in the process of PTG as Calhoun and Tedeschi (2006) suggest, but not to carry out a cross cultural study per se. The study did not intend to draw any general sociocultural comparisons. Third, the role of social support in the PTG process is multifaceted, and this study did not permit analyses of all aspects contributing to PTG occurrence. The EST guided the analyses of sociocultural elements in which personality factors were not studied in depth. More qualitative and quantitative research is needed to deepen understanding of the transformational growth that may take place in persons who lose vision in adulthood, as this population exhibits a high risk of PTEs. Tedeschi and Moor's (2016) program facilitating PTG with expert companionship seems to be aligned with participants' need to have the company of someone who is present, listens and provides trust and a sense of security. The expert companionship program can be recommended to clinicians as well as lay people who accompany persons who have lost vision after many years of being sighted.
Posttraumatic growth in persons with vision impairment 


\section{CONCLUSIONS}

This study has sought to identify changes and common processes following the adversity of vision loss in adulthood; in particular, the role of social support leading to PTG has been the main focus of this study. Social support contributed in many ways to the participants' experience of PTG after sight loss. Seeking and receiving social support proved to be an important coping strategy in facing VI. The relation charac-
Bożena $M$. Sztonyk, Zbigniew S. Formella terised by synergy between social support, gratitude, and growth has been observed. The trajectories of PTG in these studies varied and were influenced by individual resources and the sociocultural contexts of the participants.

\section{References}

Adamczyk, K. (2013). Development and validation of the Polish-language version of the Multidimensional Scale of Perceived Social Support (MSPSS). International Review of Social Psychology, 26, 25-48.

Aldwin, C. M. (1994). Transformational coping. In C. M. Aldwin (Ed.), Stress, coping, and development (pp. 240-269). New York: Guilford.

Baxter, P., \& Jack, S. (2008). Qualitative case study methodology: Study design and implementation for novice researchers. The Qualitative Report, 13, 544-559.

Boerner, K., \& Wang, S. W. (2010). How it matters when it happens: Life changes related to functional loss in younger and older adults. International Journal of Aging \& Human Development, 70, 163-179. https://doi.org/10.2190/AG.70.2.d

Boerner, K., Wang, S. W., \& Cimarolli, V. R. (2006). The impact of functional loss: Nature and implications of life changes. Journal of Loss and Trauma, 11, 265287. https://doi.org/10.1080/15325020600662625

Bronfenbrenner, U. (1979). The ecology of human development: Experiments by nature and design. Cambridge, MA, London: Harvard University Press.

Bronfenbrenner, U., \& Morris, P. A. (2006). The bioecological model of human development. In W. Damon \& R. M. Lerner (Eds.), Handbook of child psychology (6th ed., pp. 793-828). New York: Wiley.

Brunes, A., Hansen, M. B., \& Heir, T. (2018). Posttraumatic stress reactions among individuals with visual impairments: a systematic review. Disability and Rehabilitation, 41, 2111-2118. https://doi.or g/10.1080/09638288.2018.1459884

Calhoun, L. G., \& Tedeschi, R. G. (1991). Perceiving benefits in traumatic events: Some issues for practicing psychologists. The Journal of Training and Practice in Professional Psychology, 5, 45-52.

Calhoun, L. G., \& Tedeschi, R. G. (2004). The foundations of posttraumatic growth: New considerations. Psychological Inquiry, 15, 93-102.
Calhoun, L. G., \& Tedeschi, R. G. (2006). The foundations of posttraumatic growth: an expanded framework. In L. G. Calhoun \& R. G. Tedeschi (Eds.), Handbook of posttraumatic growth: Research and practice (pp. 3-23). Mahwah, NJ, London: Lawrence Erlbaum.

Calhoun, L. G., \& Tedeschi, R. G. (2013). Posttraumatic growth in clinical practice. New York: Routledge.

Carter, N., Bryant-Lukosius, D., DiCenso, A., Blythe, J., \& Neville, A. J. (2014). The use of triangulation in qualitative research. Oncology Nursing Forum, 41, 545-547. https://doi.org/10.1188/14.ONF.545-547

Colenbrander, A. (2010). Assessment of functional vision and its rehabilitation. Acta Ophthalmologica, 88, 163-173. https://doi.org/10.1111/j.17553768.2009.01670.x

Creswell, J.W. (2014). Research design: Qualitative, quantitative, and mixed methods approaches (4th ed.). Los Angeles, CA: Sage.

Frankl, V. E. (1997). Man's search for meaning. London: Pocket Books.

Hancock, D. R., \& Algozzine, R. (2006). Doing case study research: a practical guide for beginning researchers. New York: Teachers College Press.

Helgeson, V. S., Reynolds, K. A., \& Tomich, P. L. (2006). A meta-analytic review of benefit finding and growth. Journal of Consulting and Clinical Psychology, 74, 797-816. https://doi.org/10.1037/0022006X.74.5.797

Hobfoll, S. E., Hall, B. J., Canetti-Nisim, D., Galea, S., Johnson, R. J., \& Palmieri, P. A. (2007). Refining our understanding of traumatic growth in the face of terrorism: Moving from meaning cognitions to doing what is meaningful. Applied Psychology, 56, 345-366. https://doi.org/10.1111/j.1464-0597.2007. 00292.x

Janoff-Bulman, R. (1992). Shattered assumptions: Towards a new psychology of trauma. New York: Free Press.

Joseph, S. (2009). Growth following adversity: Positive psychological perspectives on posttraumatic stress. Psychological Topics, 18, 335-344.

Joseph, S. (2011). What doesn't kill us: The new psychology of posttraumatic growth. London: Piatkus.

Joseph, S. (2019). Posttraumatic growth as a process and an outcome: Vexing problems and paradoxes seen from the perspective of humanistic psychology. The Humanistic Psychologist. Advance online publication. https://doi.org/10.1037/hum0000156

Joseph, S., \& Linley, P. A. (2005). Positive adjustment to threatening events: an organismic valuing theory of growth through adversity. Review of General Psychology, 9, 262-280. https://doi. org/10.1037/1089-2680.9.3.262

Joseph, S., \& Linley, P. A. (2008). Positive psychological perspectives on posttraumatic stress: an integrative psychological framework. In S. Joseph \& P. A. Linley (Eds.), Trauma, recovery, and growth: 
Positive psychological perspectives on posttraumatic stress (pp. 3-20). Hoboken, NJ, Chichester: Wiley.

Joseph, S., Maltby, J., Wood, A. M., Stockton, H., Hunt, N., \& Regel, S. (2012). The Psychological Well-Being - Post-Traumatic Changes Questionnaire (PWB-PTCQ): Reliability and validity. Psychological Trauma: Theory, Research, Practice, and Policy, 4, 420-428. https://doi.org/10.1037/a0024740

Juczyński, Z., \& Ogińska-Bulik, N. (2012). In spite of adversity - posttraumatic growth in the aftermath of experienced negative life events. In J. Binnenbesel, Z. Formella, P. Krakowiak, \& Z. Domzał (Eds.), Experiencing suffering (pp. 301-319). RomaLodz: Libreria Ateneo Salesiano \& Wydawnictwo WSEZiNS.

Linley, P. A. (2003). Positive adaptation to trauma: Wisdom as both process and outcome. Journal of Traumatic Stress, 16, 601-610. https://doi. org/10.1023/B:JOTS.0000004086.64509.09

Linley, P. A., \& Joseph, S. (2004). Positive change following trauma and adversity: a review. Journal of Traumatic Stress, 17, 11-21. https://doi.org/10.1023/ B:JOTS.0000014671.27856.7e

Morris, B. A., Shakespeare-Finch, J., Rieck, M., \& Newbery, J. (2005). Multidimensional nature of posttraumatic growth in an Australian population. Journal of Traumatic Stress, 18, 575-585. https://doi. org/10.1002/jts.20067

Morris, B. A., Shakespeare-Finch, J., \& Scott, J. L. (2012). Posttraumatic growth after cancer: The importance of health-related benefits and newfound compassion for others. Supportive Care in Cancer, 20, 749756. https://doi.org/10.1007/s00520-011-1143-7

Ogińska-Bulik, N. (2013). The role of social support in posttraumatic growth in people struggling with cancer. Health Psychology Report, 1, 1-8. https:// doi.org/10.5114/hpr.2013.40464

Ogińska-Bulik, N., \& Juczyński, Z. (2010). Rozwój potraumatyczny - charakterystyka i pomiar [Posttraumatic growth - characteristic and measurement]. Psychiatria, 7, 129-142.

O'Leary, V. E., \& Ickovics, J. R. (1995). Resilience and thriving in response to challenge: an opportunity for a paradigm shift in women's health. Women's Health, 1, 121-142.

Park, C. L., Cohen, L. H., \& Murch, R. L. (1996). Assessment and prediction of stress-related growth. Journal of Personality, 64, 71-105. https://doi. org/10.1111/j.1467-6494.1996.tb00815.x

Pascolini, D., \& Mariotti, S. P. (2012). Global estimates of visual impairment: 2010. The British Journal of Ophthalmology, 96, 614-618. https://doi. org/10.1136/bjophthalmol-2011-300539

Prati, G., \& Pietrantoni, L. (2009). Optimism, social support, and coping strategies as factors contributing to posttraumatic growth: a meta-analysis. Journal of Loss and Trauma, 14, 364-388. https:// doi.org/10.1080/15325020902724271
Senra, H., Barbosa, F., Ferreira, P., Vieira, C. R., Perrin, P. B., Rogers, H., Rivera, D., \& Leal, I. (2015). Psychologic adjustment to irreversible vision loss in adults: a systematic review. Ophthalmology, 122, 851-861. https://doi.org/10.1016/j.ophtha.2014.10. 022

Tedeschi, R. G., \& Calhoun, L. G. (1996). The Posttraumatic Growth Inventory: Measuring the positive legacy of trauma. Journal of Traumatic Stress, 9, 455-471. https://doi.org/10.1007/BF02103658

Tedeschi, R. G., \& Moore, B. A. (2016). The posttraumatic growth workbook: Coming through trauma wiser, stronger, and more resilient. Oakland, CA: New Harbinger Publications.

Tedeschi, R. G., Park, C. L., \& Calhoun, L. G. (1998). Posttraumatic growth: Conceptual issues. In R. G. Tedeschi, C. L. Park, \& L. G. Calhoun (Eds.), The LEA series in personality and clinical psychology. Posttraumatic growth: Positive changes in the aftermath of crisis (pp. 1-22). Mahwah, NJ: Erlbaum.

Tedeschi, R. G., Shakespeare-Finch, J., Taku, K., \& Calhoun, L. G. (2018). Posttraumatic growth: Theory, research and applications. London: Routledge.

Vishnevsky, T., Cann, A., Calhoun, L. G., Tedeschi, R. G., \& Demakis, G. J. (2010). Gender differences in self-reported posttraumatic growth: a meta-analysis. Psychology of Women Quarterly, 34, 111-120. https://doi.org/10.1111/j.1471-6402.2009.01546.x

Wong, P. T. P. (2011). Positive psychology 2.0: Towards a balanced interactive model of the good life. Canadian Psychology, 52, 69-81. https://doi. org/10.1037/a0022511

Wood, A. M., Joseph, S., \& Linley, P. A. (2007). Coping style as a psychological resource of grateful people. Journal of Social and Clinical Psychology, 26, 10761093. https://doi.org/10.1521/jscp.2007.26.9.1076

Wood, A. M., Maltby, J., Gillett, R., Linley, P. A., \& Joseph, S. (2008). The role of gratitude in the development of social support, stress, and depression: Two longitudinal studies. Journal of Research in Personality, 42, 854-871. https://doi.org/10.1016/j. jrp.2007.11.003

World Health Organization (2016). International Classification of Diseases (ICD-10). Retrieved from https://icd.who.int/browse10/2016/en\#/H53-H54

Yalom, I. D., \& Lieberman, M. A. (1991). Bereavement and heightened existential awareness. Psychiatry: Interpersonal and Biological Processes, 54, 334-345. https://doi.org/10.1080/00332747.1991.11024563

Zimet, G. D., Dahlem, N. W., Zimet, S. Z., \& Farley, G. K. (1988). The Multidimensional Scale of Perceived Social Support. Journal of Personality Assessment, 52, 30-41. https://doi.org/10.1207/s15327752jpa5201_2
Posttraumatic growth in persons with vision impairment 